\author{
Disponible en ligne sur \\ SciVerse ScienceDirect \\ www.sciencedirect.com \\ Elsevier Masson France \\ EM|consulte \\ www.em-consulte.com
}

\title{
GLP-1 receptor agonists and heart failure in diabetes
}

\author{
André J. Scheen ${ }^{1,2}$ \\ ${ }^{1}$ Division of Diabetes, Nutrition and Metabolic Disorders, Department of Medicine, CHU Sart Tilman (B35), B-4000 Liege 1, Belgium \\ ${ }^{2}$ Clinical Pharmacology Unit, CHU Liège, Center for Interdisciplinary Research on Medicines (CIRM), University of Liège, Liège, Belgium
}

\begin{abstract}
The prevalence of heart failure (HF) is increasing in patients with type 2 diabetes (T2D), and glucose-lowering agents have distinctive effects on the risk of developing $\mathrm{HF}$ that requires hospitalization. Such an increased risk has been consistently reported with thiazolidinediones (glitazones) and perhaps also with the dipeptidyl peptidase (DPP)-4 inhibitor saxagliptin (at least in SAVOR - TIMI 53), whereas a markedly decreased risk was highlighted with the sodium - glucose cotransporter type 2 (SGLT2) inhibitor empagliflozin in EMPA-REG OUTCOME. Yet, the effects of glucagon-like peptide-1 receptor agonists (GLP-1RAs) on myocardial function remain controversial. Whereas some promising observations have been reported in various animal models, the effects of GLP-1RAs on myocardial function in humans are more heterogeneous, while the positive effect on left ventricular ejection fraction (LVEF), if any, appears to be inconsistent and rather modest in most patients with HF. However, no increased risk of hospitalization for HF has been reported with GLP-1RAs in meta-analyses of phase-II/III trials (exenatide, albiglutide, dulaglutide, liraglutide), demonstrating the safety of this pharmacological class, and such findings have been confirmed by three large prospective cardiovascular outcome trials (ELIXA with lixisenatide, LEADER with liraglutide and SUSTAIN-6 with semaglutide). In particular, LEADER reported a trend towards a reduction in HF hospitalization $(-13 \%, P=0.14)$, together with a significant reduction in cardiovascular and all-cause mortality in patients with T2D at risk of cardiovascular disease. These results are reassuring in the face of the somewhat negative results of the FIGHT trial, which evaluated the effects of liraglutide in patients with advanced HF and low LVEF, such that further studies and caution are now required when using this agent to treat such patients in clinical practice.
\end{abstract}

(C) 2017. Elsevier Masson SAS. All rights reserved

Key words: Congestive heart failure; Cardiac function; GLP-1 receptor agonist; LEADER; Liraglutide; Type 2 diabetes

\section{Introduction}

Both the increasing number of older patients with type 2 diabetes (T2D) and improved survival of diabetic patients with acute coronary syndrome have resulted in a massive increase in patients with both T2D and heart failure (HF). It is also noteworthy that, besides advanced age, all the major risk factors for $\mathrm{HF}$ are clustered in patients with T2D, including obesity, hypertension, sleep apnoea, coronary heart disease and chronic kidney disease [1]. Therefore, the precise role of hyperglycaemia in the development of cardiovascular disease in general, and HF in particular, in patients with T2D remains controversial [2]. Diabetes may also cause cardiac dysfunction in the absence of overt macrovascular disease due to hyperglycaemia-related cardiomyopathy, even in patients in type 1 diabetes [3]. HF is of major interest as it is the one cardiovascular outcome for which the risk has unequivocally been shown to be increased by some glucose-lowering therapies, particularly thiazolidinediones (glitazones) [4,5], whereas metformin appears to be safe [6]. Recently, some concerns have also been raised with the dipeptidyl peptidase (DPP)-4 inhibitor saxagliptin, following the publication of the Saxagliptin Assessment of Vascular Outcomes Recorded in Patients with Diabetes Mellitus (SAVOR) - Thrombolysis in Myocardial Infarction (TIMI) 53 trial [7], a finding that casts some suspicion on the entire incretin-based pharmacological class [8-10]. In contrast, a marked, significant reduction in hospitalizations for $\mathrm{HF}$ has been reported with the sodium - glucose cotransporter type 2 (SGLT2) inhibitor empagliflozin in the Empagliflozin Cardiovascular Outcome Event Trial in Type 2 Diabetes Mellitus Patients (EMPA-REG OUTCOME) [11,12]. Because hospital admission for HF is a common and serious factor associated with a higher risk of death, HF is a cardiovascular outcome that can no longer be ignored in diabetic patients, especially when choosing a glucose-lowering agent [13].

Incretin-based therapies, including oral DPP-4 inhibitors and injectable glucagon-like peptide-1 receptor agonists

Correspondence.

E-mail address: andre.scheen @ chu.ulg.ac.be (A. J. Scheen). 
(GLP-1RAs), are increasingly being used for the management of T2D [14]. During recent years following the request of the US Food and Drug Administration (FDA), special attention has been focused on their cardiovascular effects [15-18], and greater concerns surfaced after the report of a higher incidence of hospitalization for HF with the DPP-4 inhibitor saxagliptin $[7,8]$.

Thus, the primary objective of the present review is to succinctly discuss the effects of GLP-1RAs on cardiac function, focusing only on human studies to be concise. Recent reviews have summarized animal data in both ischaemic and reperfused myocardium, and in other conditions associated with myocardial remodelling and $\mathrm{HF}$, as well as the results of experimental studies, and all have contributed to a better understanding of the molecular mechanisms and intracellular pathways involved in the myocardial protection induced by GLP-1 $[15,19,20]$. In addition, other reviews have focused on the effects of GLP-1RAs on biomarkers and cardiovascular risk factors $[21,22]$. Overall, the available set of data seems to suggest that GLP-1 analogues mimicking the action of endogenous GLP-1 could be considered a novel therapeutic strategy in diabetic patients with cardiovascular disease and HF [23]. The second review objective is to analyze the results of clinical trials that have investigated the effects of different GLP-1RAs on the risk of HF, especially the risk of hospitalization for HF, in patients with T2D. As most of the studies of patients with or at risk of HF have involved liraglutide, a special place has been reserved for this GLP-1RA, which was evaluated in the large-scale Liraglutide Effect and Action in Diabetes: Evaluation of Cardiovascular Outcome Results (LEADER) trial [24].

\section{GLP-1 and cardiac function}

Following an initial open-label pilot study of GLP-1 treatment of myocardial function in patients with T2D and HF [25], a few controlled trials have been performed, but mostly in a limited number of patients with a left ventricular ejection fraction $(\mathrm{LVEF})<40 \%$. Mild improvements were observed in some studies [26,27], whereas no significant changes in LVEF were noted in others [28,29] (Table 1).

Similar mitigating results were reported with an infusion of exenatide $(0.12 \mathrm{pmol} / \mathrm{kg} / \mathrm{min}$ for $6 \mathrm{~h})$ in $20 \mathrm{~T} 2 \mathrm{D}$ patients with $\mathrm{HF}$ and $\mathrm{LVEF} \leq 35 \%$ vs saline infusion in a crossover trial [30]. A significant increase in cardiac output was observed, mainly due to a significant increase in heart rate, but stroke volume remained almost unchanged with exenatide $v s$ saline [30].

All these results have been summarized in a meta-analysis dedicated to the effects of GLP-1RAs in HF [31]. Its conclusion was that the use of GLP-1RAs has, at best, only a modest effect on LVEF improvement in patients with congestive heart failure [CHF; $+4.4 \%, 95 \%$ confidence interval (CI): 1.36-7.44; $P=0.005$ vs placebo], with no significant improvements in brain natriuretic peptide (BNP) levels. However, the small number of studies, the limited number of subjects in each trial, and the variations in dosage and duration of therapy among the trials somewhat limit these conclusions [31].

In addition, a recent study performed in T2D patients with HF (New York Heart Association II or III) and LVEF $<40 \%$ showed that treatment with the new GLP-1RA albiglutide (30 mg once a week for 12 weeks) compared with a placebo did not significantly improve LVEF, the 6-min walk test, or myocardial glucose or oxygen use [32].

\section{GLP-1RAs and heart failure risk}

The effects of GLP-1RAs on the risk of developing HF in patients with T2D have been analyzed by two large metaanalyses of phase-II/III randomized controlled trials (RCTs; Table 2) [33,34]. The first meta-analysis provided data for all the GLP-1RAs combined and for each individual GLP-1RA (albiglutide, dulaglutide, exenatide and liraglutide) [33]. When considering all 20 pooled trials, the risk of HF was lower with GLP-1RAs than with the comparators [hazard

\begin{tabular}{|c|c|c|c|c|c|}
\hline \multicolumn{6}{|c|}{$\begin{array}{l}\text { Table } 1 \\
\text { Effects of glucagon-like peptide (GLP)-1 intravenous infusion on left ventricular ejection fraction (LVEF) in patients with or without diabetes and hea } \\
\text { failure }\end{array}$} \\
\hline Reference & GLP-1 vs saline (n) & Patient characteristics & $\begin{array}{l}\text { Treatment duration/dose } \\
(\mathrm{pmol} / \mathrm{kg} / \mathrm{min})\end{array}$ & $\begin{array}{l}\text { Saline-subtracted LVEF } \\
\text { change }(\%)\end{array}$ & $P$ \\
\hline $\begin{array}{l}\text { Thrainsdottir et al., } \\
2004 \text { [25] }\end{array}$ & 6 vs 0 (pilot) & $\begin{array}{l}\mathrm{CHF} \\
\mathrm{LVEF}<40 \%\end{array}$ & $72 \mathrm{~h} / 3-4$ & $\begin{array}{l}\text { Trend towards slight } \\
\text { improvement }\end{array}$ & NS \\
\hline $\begin{array}{l}\text { Nikolaidis et al., } \\
2004[26]\end{array}$ & $10 v s 11$ & $\begin{array}{l}\text { Acute MI } \\
\text { LVEF }<40 \%\end{array}$ & $72 \mathrm{~h} / 1.5$ & +9 & $<0.01$ \\
\hline $\begin{array}{l}\text { Sokos et al., } \\
2006[27]\end{array}$ & $12 v s 9$ & $\begin{array}{l}\mathrm{CHF} \\
\mathrm{LVEF} \leq 40 \%\end{array}$ & 5 weeks $/ 2.5$ & +5 & $<0.001$ \\
\hline $\begin{array}{l}\text { Sokos et al., } \\
2007[28]\end{array}$ & 10 vs 10 & $\begin{array}{l}\text { CABG without CHF* } \\
\text { LVEF }>40 \%\end{array}$ & $60 \mathrm{~h} / 1.5$ & +1 & NS \\
\hline $\begin{array}{l}\text { Halbirk et al., } \\
2010[29]\end{array}$ & $15 v s 15$ & $\begin{array}{l}\mathrm{CHF} \\
\mathrm{LVEF}<40 \%\end{array}$ & $48 \mathrm{~h} / 1.0$ & +2 & NS \\
\hline
\end{tabular}




\begin{tabular}{|c|c|c|c|c|c|}
\hline \multicolumn{6}{|l|}{$\begin{array}{l}\text { Table } 2 \\
\text { Effects of } \\
\text { of phase- }\end{array}$} \\
\hline Reference & GLP-1RA & Trials (n) & $\begin{array}{l}\text { GLP-1RA: HF events/ } \\
\text { patients }\end{array}$ & $\begin{array}{l}\text { Control: HF events/ } \\
\text { patients }\end{array}$ & OR $(95 \% \mathrm{CI})$ \\
\hline \multirow[t]{5}{*}{ Li et al., 2016 [33] } & All & 20 & $17 / 7441$ & $19 / 4317$ & $0.62(0.31-1.02)$ \\
\hline & Albiglutide & 5 & $5 / 1427$ & $11 / 1293$ & $0.39(0.14-1.07)$ \\
\hline & Dulaglutide & 4 & $5 / 2231$ & $2 / 967$ & $1.12(0.22-5.61)$ \\
\hline & Exenatide & 5 & 2/991 & $4 / 842$ & $0.51(0.10-2.54)$ \\
\hline & Liraglutide & 5 & $5 / 2298$ & 0/1099 & $4.85(0.75-31.36)$ \\
\hline \multirow{3}{*}{$\begin{array}{l}\text { Wang et al., } \\
2016 \text { [34] }\end{array}$} & Exenatide & 5 & $4 / 1392$ & $2 / 1371$ & $1.92(0.39-9.50)$ \\
\hline & Liraglutide & 3 & $5 / 1361$ & $0 / 748$ & $5.52(0.90-33.95)$ \\
\hline & Albiglutide & 5 & $6 / 1427$ & $12 / 1293$ & $0.45(0.17-1.17)$ \\
\hline $\begin{array}{l}\text { Fisher et al., } 2016 \\
\text { [35] }\end{array}$ & Albiglutide & $8^{*}$ & $14 / 2424$ & $11 / 2583$ & 1.36 (NA) \\
\hline $\begin{array}{l}\text { Ferdinand et al., } \\
2016[36]\end{array}$ & Dulaglutide & $9 *$ & $7 / 3885$ & $2 / 2125$ & $2.02(0.41-9.88)$ \\
\hline
\end{tabular}

ratio (HR): 0.62, 95\% CI: 0.31-1.02]. Subgroup analyses of HF risk with each individual GLP-1RA suggested a possible differential treatment effect across individual agents ( $P=0.07$ for interaction), with liraglutide associated with a non-significant increased risk of HF [odds ratio (OR): 4.85, 95\% CI: 0.75-31.36]; this finding was, however, based on a limited number of events (five in total) and a very wide CI [33]. Nevertheless, these data were confirmed in the second meta-analysis reporting the HR for exenatide, albiglutide and liraglutide (Table 2) [34]. In two other metaanalyses specifically dedicated to either albiglutide [35] or dulaglutide [36], neither reported any significantly increased risk of hospitalization for HF (Table 2).

All these data confirm the cardiovascular safety of GLP-1RAs [37]. Indeed, these meta-analyses of RCTs with GLP-1RAs may be compared with those of RCTs with DPP-4 inhibitors $[9,10]$, which showed that DPP-4 inhibitors were not associated with any increased risk of HF-related hospitalizations [10] except for saxagliptin [9], mainly because of the results of the SAVOR - TIMI 53 trial [7].

In a retrospective cohort study of members of a large US health system, only one subject treated with GLP-1RAs was hospitalized for HF, making comparison with the controls impossible. Those treated with GLP-1RAs had lower risks of all-cause hospitalization (HR: $0.17,95 \%$ CI: 0.02-1.23; $P=0.079$ ) and all-cause death (HR: 0.17, 95\% CI: 0.02-1.22; $P=0.078$ ), although these estimates did not reach statistical significance [38]. In addition, healthcare data from four Canadian provinces, the US and the UK were used for a nested case - control analysis [39]. The cohorts included a total of $1,499,650$ patients, with 29,741 hospitalized for HF. These rates did not increase with the use of incretin-based drugs compared with other oral antidiabetic agents, and the results were similar for both DPP-4 inhibitors and GLP-1 analogues. For purposes of comparisons, the results of the incidence of hospitalization for HF with GLP-1RAs may be summarized as follows: patients with an HF history: 231/23,205 (1.0\%) in case patients $v s$ 4120/435,777 (0.9\%) in controls (HR: 0.95, 95\% CI: 0.83-1.10); and patients with no HF history: $35 / 6536(0.5 \%)$ in case patients vs $743 / 100,480(0.7 \%)$ in controls (HR: $0.75,95 \%$ CI: 0.22-2.51). The duration of treatment with GLP-1RAs ( $<1$ year, $1-2$ years, $>2$ years $)$ did not alter these results. Thus, in this analysis of data from large cohorts of patients with diabetes, GLP-1RAs were not associated with any increased risk of hospitalization for HF compared with the commonly used combinations of oral antidiabetic drugs [39].

\section{Effects of liraglutide on cardiac function and cardiovascular events in HF patients}

Several studies have investigated the effects of liraglutide on cardiac function in patients with or without diabetes, and with either coronary heart disease (with preserved LVEF) [40-42] or CHF and reduced LVEF $(<40 \%)$ [43-45]. The results were widely heterogeneous. Indeed, three studies reported a significant increase in LVEF in patients with preserved LVEF [40,41] and reduced LVEF [43], whereas three other studies - one in patients with preserved cardiac function [42] and two in patients with altered function $[44,45]$ - reported almost no changes in LVEF with liraglutide compared with a placebo (Table 3 ). The two largest trials, with follow-ups of about 6 months, also reported virtually no changes in LVEF $[44,45]$. Thus, it may be concluded that the effect of liraglutide on LVEF is, if anything, modest and probably not clinically relevant. 


\begin{tabular}{|c|c|c|c|c|c|}
\hline \multicolumn{6}{|c|}{$\begin{array}{l}\text { Table } 3 \\
\text { Effects of liraglutide (titrated up to } 1.8 \mathrm{mg} / \text { day) } v s \text { placebo on left ventricular ejection fraction (LVEF) in patients with coronary heart disease or } \\
\text { congestive heart failure }\end{array}$} \\
\hline Reference & $\begin{array}{l}\text { Liraglutide } v s \\
\text { placebo (n) }\end{array}$ & Patient characteristics & $\begin{array}{l}\text { Treatment duration } \\
\text { (weeks) }\end{array}$ & $\begin{array}{l}\text { Mean LVEF change } \%(95 \% \\
\text { CI })\end{array}$ & $P$ \\
\hline \multicolumn{6}{|c|}{ Patients with coronary heart disease (CHD) and preserved LVEF } \\
\hline Chen et al., 2015 [40] & 45 vs 47 & $\begin{array}{l}\text { STEMI + PCI } \\
\mathrm{LVEF}>40 \%\end{array}$ & $1^{\mathrm{a}}$ & $+4.1(+1.1,+6.9)$ & $<0.001$ \\
\hline Chen et al., 2016 [41] & 45 vs 45 & $\begin{array}{l}\text { Non-STEMI } \\
\text { LVEF }>40 \%\end{array}$ & $1^{\mathrm{a}}$ & $+4.7(+0.7,+9.2)$ & 0.009 \\
\hline $\begin{array}{l}\text { Kamarathurai et al., } \\
2016 \text { [42] }\end{array}$ & 17 vs 13 & $\begin{array}{l}\text { CHD } \\
\mathrm{LVEF}>40 \%\end{array}$ & 12 & $+0.54(-2.38,+3.45)$ & 0.710 \\
\hline \multicolumn{6}{|c|}{ Patients with congestive heart failure and reduced LVEF } \\
\hline $\begin{array}{l}\text { Margulies et al., } \\
2016 \text { [45] }\end{array}$ & 154 vs 146 & $\mathrm{LVEF} \leq 40 \%$ & 26 & $+1.1(-0.7,+2.8)$ & 0.95 \\
\hline Jorsal et al., 2017 [44] & 122 vs 119 & $\mathrm{LVEF} \leq 45 \%$ & 24 & $-0.8(-2.1,+0.5)$ & 0.24 \\
\hline Arturi et al., 2016 [43] & $10 v s 10 \mathrm{~b}$ & $\mathrm{LVEF}<45 \%$ & 52 & $+4.1(\mathrm{NA})$ & $<0.001$ \\
\hline
\end{tabular}

These findings are expected to be confirmed by the Liraglutide in Young Adults with Type 2 Diabetes (LYDIA), a prospective randomized, open-label, active-comparator ( $v s$ sitagliptin) trial. The study will comprehensively describe changes in various parameters of cardiac structure and function in patients treated with liraglutide to provide new evidence of the effects of liraglutide on diastolic function in young obese patients with T2D [46].

The Functional Impact of GLP-1 for Heart Failure Treatment (FIGHT) study has tested the hypothesis that sustained therapy with liraglutide (up-titrated to $1.8 \mathrm{mg}$ ), initiated within 14 days of hospitalization for an acute HF syndrome (despite already receiving evidence-based therapies, including furosemide), is associated with greater clinical stability throughout 180 days in patients with or without T2D, and with advanced HF and reduced LVEF $(\leq 40 \%)$ [45]. The primary endpoint was a global score in which patients were ranked across three hierarchical tiers: time to death; time to rehospitalization for HF; and time-averaged proportional change in N-terminal pro-BNP levels from baseline to 180 days. Compared with placebo, liraglutide had no significant effect on the primary endpoint (mean rank score of 146 for the liraglutide group $v s 156$ for the placebo group; $P=0.31$ ). There were also no significant between-group differences in number of deaths (HR: $1.10,95 \% \mathrm{CI}: 0.57-2.14 ; P=0.78$ ) or rehospitalizations for $\mathrm{HF}$, whereas a trend towards higher risk was noted (HR: 1.30, 95\% CI: 0.89-1.88; $P=0.17$ ). Similarly, no significant between-group differences were reported for the different exploratory secondary endpoints (primary endpoint components plus cardiac structure and function, 6-min walk test, quality of life and combined events). In addition, prespecified subgroup analyses restricted to only patients with T2D failed to reveal any significant between-group differences [45]. Thus, in patients recently hospitalized for HF and a reduced LVEF, the use of liraglutide did not lead to greater post-hospitalization clinical stability. Thus, these findings do not support the use of liraglutide in such a clinical situation.

\section{Lessons from LEADER}

In this double-blind trial, patients with T2D and high cardiovascular risk were randomly assigned to receive liraglutide titrated up to $1.8 \mathrm{mg}$ once daily $(n=4668)$ or placebo $(n=4672)$ [24]. The primary composite outcome in the time-to-event analysis was the first occurrence of death from cardiovascular causes, non-fatal myocardial infarction or non-fatal stroke. Hospitalization for HF was part of a prespecified exploratory outcome involving an expanded composite cardiovascular outcome.

The primary outcome was observed in significantly fewer patients in the liraglutide group (608 of 4668 patients, $13.0 \%$ ) than in the placebo group (694 of 4672, 14.9\%; HR: 0.87, 95\% CI: $0.78-0.97 ; P=0.01$ for superiority). Fewer patients died due to either cardiovascular causes (HR: 0.78, 95\% CI: $0.66-0.93 ; P=0.007$ ) or any cause (HR: $0.85,95 \% \mathrm{CI}$ : $0.74-0.97 ; P=0.02)$ in the liraglutide group than in the placebo group, with a trend towards a lower incidence of non-fatal myocardial infarction and non-fatal stroke. The reduction in the composite primary cardiovascular outcome did not differ significantly between subjects, whether with ( $n=1305$; HR: $0.94,95 \%$ CI: $0.72-1.21)$ or without $(n=8035$; HR: $0.85,95 \%$ CI: $0.76-0.96) \mathrm{HF}$ at baseline $(P=0.53$ for interaction). Interestingly, there were fewer hospitalizations for HF $(-13 \% ; P=0.14)$ among patients with liraglutide than with the placebo, although the difference was not significant 
(Table 4) [24]. It should be noted, however, that hospitalization for HF was only part of the prespecified exploratory, expanded, composite cardiovascular outcome of LEADER, as well as other RCTs, in patients with T2D and high cardiovascular risk. As previously discussed [13], the universal lack of large-scale trials of the use of the new glucose-lowering drugs for hospital admissions for $\mathrm{HF}$ as a prespecified component of the primary composite cardiovascular outcome is a major concern, given the high prevalence and seriousness of this situation among T2D patients.

In fact, the lack of any significant difference in the risk of hospitalizations for HF between those treated with a GLP-1RA or a placebo reported with liraglutide in LEADER [24] was confirmed with lixisenatide in the Evaluation of Lixisenatide in Acute Coronary Syndrome (ELIXA) trial [47] and with semaglutide in the Trial to Evaluate Cardiovascular and Other Long-term Outcomes with Semaglutide in Subjects with Type 2 Diabetes (SUSTAIN-6; Table 4) [48]. Unfortunately, no measurements of pro-BNP levels were available in the LEADER trial [24], and this key information was also missing in the ELIXA [47] and SUSTAIN-6 [48]. However, such measurements were included in two trials of DPP-4 inhibitors: the EXAMINE with alogliptin [49]; and SAVOR - TIMI 53 with saxagliptin [50]. In EXAMINE, alogliptin had no effect on the composite events of cardiovascular death and hospital admission for HF on post-hoc analysis (HR: 1.00, 95\% CI: 0.82-1.21), and the results did not differ by baseline BNP concentration [49]. In SAVOR - TIMI 53, the increased risk of hospitalization for HF was highest among patients with elevated levels of natriuretic peptides, previous HF or chronic kidney disease [50].

Thus, the LEADER trial demonstrated that liragutide can reduce cardiovascular and all-cause mortality in T2D patients at high cardiovascular risk. The underlying mechanisms of this protection, however, remain largely unexplained, although the contributions of both indirect systemic and direct myocardial effects have been postulated [22]. In general, though, these protective mechanisms seem to differ from those proposed for empagliflozin in EMPA-REG OUTCOME [11], for which various explanations have also been put forward, yet is still controversial [51]. One marked difference between LEADER and EMPA-REG OUTCOME is the distinctive outcome of a $35 \%(P<0.001)$ reduction in hospitalizations for HF reported with empagliflozin, whereas only a slight, non-significant reduction was noted with liraglutide $(-13 \%, P=0.14$; Table 4$)$. Both liraglutide and empagliflozin reduce systolic blood pressure, an independent risk factor of $\mathrm{HF}$, but the insignificant difference vs the placebo arm in T2D patients with blood pressure already well controlled at baseline cannot explain the marked reduction in hospitalizations for HF in the EMPA-REG OUTCOME [52]. As the placebo-subtracted difference in systolic blood pressure was lower in LEADER than in EMPA-REG OUTCOME, any crucial role of blood-pressure reduction with liraglutide can most likely also be excluded. The difference between the results of these two trials regarding the effects on HF could be explained by the specific mechanism of action of the SGLT2 inhibitor targeting the kidneys and its related diuretic effect [53]. In any case, the LEADER trial has demonstrated the safe use of the GLP-1RA liraglutide in patients at high cardiovascular risk with no increased incidence of HF. Nevertheless, given the negative results of the FIGHT study [45], the use of liraglutide should be recommended with caution in patients with advanced HF and reduced LVEF, and further studies are now also required in this particular patient population.

\section{Conclusion}

$\mathrm{HF}$ is an increasingly common complication among patients with $\mathrm{T} 2 \mathrm{D}$, and the various glucose-lowering agents used in the management of T2D have distinctive effects on the risk of hospitalization for HF. Incretin-based therapies have been scrutinized, especially after the SAVOR - TIMI 53 trial showed a significantly greater incidence of HF hospitalizations in T2D patients with antecedents of cardiovascular disease receiving saxagliptin $v s$ placebo. However, this effect was not confirmed in other trials using different DPP-4 inhibitors. Yet, despite the promising preliminary results from animal models, in general, GLP-1RAs either do not, or only slightly and inconsistently, improve myocardial function in patients with coronary artery disease or HF with

\begin{tabular}{|c|c|c|c|c|c|}
\hline Trial & $\begin{array}{l}\text { GLP-1RA } \\
\text { (median follow-up) }\end{array}$ & $\begin{array}{l}\text { GLP-1RA } \\
\text { events/patients (\%) } \\
\text { Events/person-years }\end{array}$ & $\begin{array}{l}\text { Placebo } \\
\text { events/patients }(\%) \\
\text { Events/person-years }\end{array}$ & $\begin{array}{l}\text { Hazard ratio } \\
(95 \% \mathrm{CI})\end{array}$ & $P^{*}$ \\
\hline ELIXA [47] & $\begin{array}{l}\text { Lixisenatide } \\
\text { ( } 2.1 \text { years) }\end{array}$ & $\begin{array}{l}122 / 3034(4.0) \\
1.8\end{array}$ & $\begin{array}{l}127 / 3034(4.2) \\
1.9\end{array}$ & $\begin{array}{l}0.96 \\
(0.75-1.23)\end{array}$ & 0.75 \\
\hline LEADER [24] & $\begin{array}{l}\text { Liragutide } \\
\text { (3.8 years) }\end{array}$ & $\begin{array}{l}218 / 4668(4.7) \\
1.2\end{array}$ & $\begin{array}{l}248 / 4672(5.3) \\
1.4\end{array}$ & $\begin{array}{l}0.87 \\
(0.73-1.05)\end{array}$ & 0.14 \\
\hline SUSTAIN-6 [48] & $\begin{array}{l}\text { Semaglutide } \\
\text { ( } 2 \text { years })\end{array}$ & $\begin{array}{l}59 / 1648(3.6) \\
1.76\end{array}$ & $\begin{array}{l}54 / 1649(3.3) \\
1.61\end{array}$ & $\begin{array}{l}1.11 \\
(0.77-1.61)\end{array}$ & 0.57 \\
\hline
\end{tabular}

* For superiority.

ELIXA: Evaluation of Lixisenatide in Acute Coronary Syndrome; LEADER: Liraglutide Effect and Action in Diabetes: Evaluation of Cardiovascular Outcome Results; SUSTAIN-6: Trial to Evaluate Cardiovascular and Other Long-term Outcomes with Semaglutide in Subjects with Type 2 Diabetes 
decreased LVEF. The risk of hospitalization for HF was not increased in several meta-analyses of phase-II/III RCTs involving different GLP-1RAs, demonstrating the safety of compounds in this pharmacological class in this respect. However, an imbalance between the liraglutide and control arms was observed, although the number of events was too limited to allow any definite conclusions to be drawn. On the other hand, the large prospective LEADER RCT in patients at high risk of cardiovascular disease has provided reassuring data, with a trend towards a lower incidence of hospitalization for HF in the liraglutide arm compared with the placebo arm, together with a markedly significant reduction in cardiovascular and all-cause mortality. Nevertheless, the results of the FIGHT trial, including a non-significant trend for more rehospitalizations for HF in patients with advanced HF and decreased LVEF treated with liraglutide, demands caution and calls for further investigation.

\section{Funding}

No sources of funding were used to assist in the preparation of this manuscript.

\section{Disclosure of interest}

A.J. Scheen has received lecture/advisor fees from AstraZeneca, Boehringer Ingelheim, Eli Lilly, GlaxoSmithKline, Janssen, Merck \& Co., Novartis, Novo Nordisk and Sanofi. He has also served as a clinical investigator in the TECOS, EMPA-REG OUTCOME and LEADER trials.

\section{References}

[1] Thomas MC. Type 2 diabetes and heart failure: challenges and solutions Curr Cardiol Rev 2016;12:249-55.

[2] Scheen AJ, Charbonnel B. Effects of glucose-lowering agents on vascular outcomes in type 2 diabetes: A critical reappraisal. Diabetes Metab 2014;40:176-85

[3] Retnakaran R, Zinman B. Type 1 diabetes, hyperglycaemia, and the heart. Lancet 2008;371:1790-9.

[4] Standl E, Schnell O, McGuire DK. Heart failure considerations of antihyperglycemic medications for type 2 diabetes. Circ Res 2016;118:1830-43.

[5] Gilbert RE, Krum H. Heart failure in diabetes: effects of anti-hyperglycaemic drug therapy. Lancet 2015;385:2107-17.

[6] Scheen AJ, Paquot N. Metformin revisited: A critical review of the benefit-risk balance in at-risk patients with type 2 diabetes. Diabetes Metab 2013;39:179-90.

[7] Scirica BM, Braunwald E, Raz I, Cavender MA, Morrow DA, Jarolim P, et al. Heart failure, saxagliptin, and diabetes mellitus: observations from the SAVOR-TIMI 53 randomized trial. Circulation 2015;132:e198.

[8] Standl E, Erbach M, Schnell O. Dipeptidyl-peptidase-4 inhibitors and heart failure: class effect, substance-specific effect, or chance effect? Curr Treat Options Cardiovasc Med 2014;16:353.

[9] Kongwatcharapong J, Dilokthornsakul P, Nathisuwan S, Phrommintikul A, Chaiyakunapruk N. Effect of dipeptidyl peptidase-4 inhibitors on heart failure: A meta-analysis of randomized clinical trials. Int J Cardiol 2016;211:88-95.

[10] Kundu A, Sardar P, Ghosh S, Patel P, Chatterjee S, Meyer TE. Risk of heart failure with dipeptidyl peptidase- 4 inhibitors in patients with type 2 diabetes mellitus: A meta-analysis of randomized controlled trials. Int J Cardiol 2016;212:203-5.
[11] Zinman B, Wanner C, Lachin JM, Fitchett D, Bluhmki E, Hantel S, et al. Empagliflozin, cardiovascular outcomes, and mortality in type 2 diabetes. N Engl J Med 2015;373:2117-28.

[12] Fitchett D, Zinman B, Wanner C, Lachin JM, Hantel S, Salsali A, et al. Heart failure outcomes with empagliflozin in patients with type 2 diabetes at high cardiovascular risk: results of the EMPA-REG OUTCOME® trial. Eur Heart J 2016;37:1526-34.

[13] McMurray JJ, Gerstein HC, Holman RR, Pfeffer MA. Heart failure: a cardiovascular outcome in diabetes that can no longer be ignored. Lancet Diabetes Endocrinol 2014;2:843-51.

[14] Nauck M. Incretin therapies: highlighting common features and differences in the modes of action of glucagon-like peptide- 1 receptor agonists and dipeptidyl peptidase-4 inhibitors. Diabetes Obes Metab 2016;18:203-16.

[15] Ussher JR, Drucker DJ. Cardiovascular actions of incretin-based therapies. Circ Res 2014;114:1788-803.

[16] White WB, Baker WL. Cardiovascular effects of incretin-based therapies. Annu Rev Med 2016;67:245-60

[17] Waldrop G, Zhong J, Peters M, Rajagopalan S. incretin-based therapy for diabetes: what a cardiologist needs to know. J Am Coll Cardiol 2016;67:1488-96.

[18] Mannucci E, Monami M. Cardiovascular safety of incretin-based therapies in type 2 diabetes: systematic review of integrated analyses and randomized controlled trials. Adv Ther 2017;34:1-40.

[19] Ravassa S, Zudaire A, Diez J. Glucagon-like peptide 1 and cardiac cell survival. Endocrinol Nutr 2012;59:561-9.

[20] Zhao TC. Glucagon-like peptide-1 (GLP-1) and protective effects in cardiovascular disease: a new therapeutic approach for myocardial protection. Cardiovasc Diabetol 2013;12:90.

[21] Verges B, Bonnard C, Renard E. Beyond glucose lowering: glucagonlike peptide-1 receptor agonists, body weight and the cardiovascular system. Diabetes Metab 2011;37:477-88.

[22] Kang YM, Jung CH. Cardiovascular effects of glucagon-like peptide-1 receptor agonists. Endocrinol Metab (Seoul) 2016;31:258-74.

[23] Khan MA, Deaton C, Rutter MK, Neyses L, Mamas MA. Incretins as a novel therapeutic strategy in patients with diabetes and heart failure. Heart Fail Rev 2013;18:141-8.

[24] Marso SP, Daniels GH, Brown-Frandsen K, Kristensen P, Mann JF, Nauck MA, et al. Liraglutide and cardiovascular outcomes in type 2 diabetes. N Engl J Med 2016;375:311-22.

[25] Thrainsdottir I, Malmberg K, Olsson A, Gutniak M, Ryden L. Initial experience with GLP-1 treatment on metabolic control and myocardial function in patients with type 2 diabetes mellitus and heart failure. Diab Vasc Dis Res 2004;1:40-3.

[26] Nikolaidis LA, Mankad S, Sokos GG, Miske G, Shah A, Elahi D, et al. Effects of glucagon-like peptide-1 in patients with acute myocardial infarction and left ventricular dysfunction after successful reperfusion. Circulation 2004;109:962-5.

[27] Sokos GG, Nikolaidis LA, Mankad S, Elahi D, Shannon RP. Glucagonlike peptide-1 infusion improves left ventricular ejection fraction and functional status in patients with chronic heart failure. J Card Fail 2006;12:694-9.

[28] Sokos GG, Bolukoglu H, German J, Hentosz T, Magovern GJ, Jr., Maher TD, et al. Effect of glucagon-like peptide-1 (GLP-1) on glycemic control and left ventricular function in patients undergoing coronary artery bypass grafting. Am J Cardiol 2007;100:824-9.

[29] Halbirk M, Norrelund H, Moller N, Holst JJ, Schmitz O, Nielsen $\mathrm{R}$, et al. Cardiovascular and metabolic effects of 48-h glucagon-like peptide-1 infusion in compensated chronic patients with heart failure. Am J Physiol Heart Circ Physiol 2010;298:H1096-102.

[30] Nathanson D, Ullman B, Lofstrom U, Hedman A, Frick M, Sjoholm A, et al. Effects of intravenous exenatide in type 2 diabetic patients with congestive heart failure: a double-blind, randomised controlled clinical trial of efficacy and safety. Diabetologia 2012;55:926-35.

[31] Munaf M, Pellicori P, Allgar V, Wong K. A meta-analysis of the therapeutic effects of glucagon-like Peptide-1 agonist in heart failure. Int J Pept 2012;2012:249827.

[32] Lepore JJ, Olson E, Demopoulos L, Haws T, Fang Z, Barbour AM, et al. Effects of the novel long-acting GLP-1 agonist, albiglutide, on cardiac function, cardiac metabolism, and exercise capacity in patients 
with chronic heart failure and reduced ejection fraction. JACC Heart failure 2016;4:559-66.

[33] Li L, Li S, Liu J, Deng K, Busse JW, Vandvik PO, et al. Glucagonlike peptide-1 receptor agonists and heart failure in type 2 diabetes: systematic review and meta-analysis of randomized and observational studies. BMC Cardiovasc Disord 2016;16:91.

[34] Wang T, Wang F, Zhou J, Tang H, Giovenale S. Adverse effects of incretin-based therapies on major cardiovascular and arrhythmia events: meta-analysis of randomized trials. Diabetes Metab Res Rev 2016;32:843-57.

[35] Fisher M, Petrie MC, Ambery PD, Donaldson J, Ye J, Mc Murray JJ. Cardiovascular safety of albiglutide in the Harmony programme: a meta-analysis. Lancet Diabetes Endocrinol 2015;3:697-703.

[36] Ferdinand KC, Botros FT, Atisso CM, Sager PT. Cardiovascular safety for once-weekly dulaglutide in type 2 diabetes: a pre-specified meta-analysis of prospectively adjudicated cardiovascular events. Cardiovasc Diabetol 2016;15:38

[37] Scheen AJ. Cardiovascular safety of albiglutide and other glucagon-like peptide-1 receptor agonists. Lancet Diabetes Endocrinol 2015;3:667-9.

[38] Velez M, Peterson EL, Wells K, Swadia T, Sabbah HN, Williams LK, et al. Association of antidiabetic medications targeting the glucagon-like peptide 1 pathway and heart failure events in patients with diabetes. J Card Fail 2015;21:2-8.

[39] Filion KB, Azoulay L, Platt RW, Dahl M, Dormuth CR, Clemens KK, et al. A multicenter observational study of incretin-based drugs and heart failure. N Engl J Med 2016;374:1145-54.

[40] Chen WR, Hu SY, Chen YD, Zhang Y, Qian G, Wang J, et al. Effects of liraglutide on left ventricular function in patients with ST-segment elevation myocardial infarction undergoing primary percutaneous coronary intervention. Am Heart J 2015;170:845-54.

[41] Chen WR, Shen XQ, Zhang Y, Chen YD, Hu SY, Qian G, et al. Effects of liraglutide on left ventricular function in patients with non-ST-segment elevation myocardial infarction. Endocrine 2016;52:516-26.

[42] Kumarathurai P, Anholm C, Nielsen OW, Kristiansen OP, Molvig J, Madsbad S, et al. Effects of the glucagon-like peptide-1 receptor agonist liraglutide on systolic function in patients with coronary artery disease and type 2 diabetes: a randomized double-blind placebo-controlled crossover study. Cardiovasc Diabetol 2016;15:105.
[43] Arturi F, Succurro E, Miceli S, Cloro C, Ruffo M, Maio R, et al. Liraglutide improves cardiac function in patients with type 2 diabetes and chronic heart failure. Endocrine 2016; Nov 9 [Epub ahead of print].

[44] Jorsal A, Kistorp C, Holmager P, Tougaard RS, Nielsen R, Hanselmann A, et al. Effect of liraglutide, a glucagon-like peptide-1 analogue, on left ventricular function in stable chronic heart failure patients with and without diabetes (LIVE)-a multicentre, double-blind, randomised, placebo-controlled trial. Eur J Heart Fail 2017;19:69-77.

[45] Margulies KB, Hernandez AF, Redfield MM, Givertz MM, Oliveira $\mathrm{GH}$, Cole R, et al. Effects of liraglutide on clinical stability among patients with advanced heart failure and reduced ejection fraction: a randomized clinical trial. JAMA 2016;316:500-8.

[46] Htike ZZ, Yates T, Brady EM, Webb D, Gray LJ, Swarbrick D, et al. Rationale and design of the randomised controlled trial to assess the impact of liraglutide on cardiac function and structure in young adults with type 2 diabetes (the LYDIA study). Cardiovasc Diabetol 2016;15:102.

[47] Pfeffer MA, Claggett B, Diaz R, Dickstein K, Gerstein HC, Kober LV, et al. Lixisenatide in patients with type 2 diabetes and acute coronary syndrome. N Engl J Med 2015;373:2247-57.

[48] Marso SP, Bain SC, Consoli A, Eliaschewitz FG, Jodar E, Leiter LA, et al. Semaglutide and cardiovascular outcomes in patients with type 2 diabetes. N Engl J Med 2016;375:1834-1844

[49] Zannad F, Cannon CP, Cushman WC, Bakris GL, Menon V, Perez AT, et al. Heart failure and mortality outcomes in patients with type 2 diabetes taking alogliptin versus placebo in EXAMINE: a multicentre, randomised, double-blind trial. Lancet 2015;385:2067-76.

[50] Scirica BM, Braunwald E, Raz I, Cavender MA, Morrow DA, Jarolim P, et al. Heart failure, saxagliptin and diabetes mellitus: observations from the SAVOR - TIMI 53 randomized trial. Circulation 2014;130:1579-88.

[51] Scheen AJ. Reduction in cardiovascular and all-cause mortality in the EMPA-REG OUTCOME trial: A critical analysis. Diabetes Metab 2016;42:71-6.

[52] Scheen AJ. Effects of reducing blood pressure on cardiovascular outcomes and mortality in patients with type 2 diabetes: focus on SGLT2 inhibitors and EMPA-REG OUTCOME. Diabetes Res Clin Pract 2016;121:204-14.

[53] Scheen AJ. Reappraisal of the diuretic effect of empagliflozin in the EMPA-REG OUTCOME trial: comparison with classic diuretics. Diabetes Metab 2016;42:224-33. 